\title{
Dynamic Nonmetropolitan Export-Base Modeling
}

\section{Thomas R. Harris, J. Scott Shonkwiler, and George E. Ebai*}

\begin{abstract}
This paper investigated a time series export-base model of nonmetropolitan Nevada counties. Confirmatory factor analysis was used to bifurcate county employment, and county basic and nonbasic employment were tested for cointegration. Employing the Granger Representation Theorem, an error correction mechanism model was estimated. Error correction mechanism model forecasts were performed and long-run forecasts were evaluated. Given current microcomputer hardware and software, this paper provides a procedure to conduct dynamic rural impact analysis by employing a dynamic export-base model.
\end{abstract}

\section{INTRODUCTION}

Estimation of impacts from industrialization or changes in resource use provides important and useful information to state, local, and/or rural decision makers. Decision makers often rely on regional economic models to forecast important regional aggregates (employment, income, etc.) as well as to analyze potential consequences of adopting alternative economic development strategies or alternative public resource management policies. The adequacy of these models often is not challenged and therefore may lead to erroneous policy decisions.

Woods, Doeksen, and Jones (1983) investigated different modeling techniques to project impacts from exogenous changes. Estimation of direct and indirect effects has been a necessary and important component of all these models. Most impact models employ either export-base or input-output models to derive economic linkages and sectoral impacts from exogenous changes. Also, results from these models are comparative static in nature and do not show changes through time as derived from dynamic analysis.

The export-base model is one of the oldest and simplest models for analysis of regional aggregate behavior from exogenous changes. Export-base argues that a county's economy may be bifurcated into two sectors, which are export, or basic, sector and nonexport, or nonbasic, sector (Andrews 1970; North 1955; Tiebout 1956).

The basic sector, which trades outside its boundaries, produces dollar flows into the local economy, which provides impetus for consequent economic development. The nonbasic sector, on the other hand, supplies local consumption

\footnotetext{
*Thomas R. Harris is a Foundation Professor in the Department of Applied Economics and Statistics and Director of the Center for Economic Development at the University of Nevada, Reno. J. Scott Shonkwiler is a Professor in the Department of Applied Economics and Statistics at the University of Nevada, Reno. George E. Ebai is a former Research Associate in the Department of Applied Economics and Statistics at the University of Nevada, Reno. This research was funded by the University of Nevada Agriculture Experiment Station Projects 5147 and 5149, the University of Nevada Foundation, and U.S. Department of Commerce, Economic Development Administration, University Center for Economic Development Grant \#07-06-03262-98.
} 
of goods and services. Activity in this sector is assumed to depend on basic sector export sales. This external demand for a region's exportable goods and services injects income into the local economy, which in turn augments local demands for nonexportable goods and services (Krikelas 1992).

Probably the most expansive use of export-base theory is in the development of export-base multipliers. The estimation of sectoral basic and nonbasic employment or income is essential for the estimation of export-base multipliers. Often the bifurcation of economic sectors has employed indirect or secondary procedures whose results may differ substantially from primary surveys (Gibson and Worden 1981). However, estimation of basic employment through primary surveys has proven to be very costly, time consuming, and subject to selection bias and accuracy errors by respondents. Since there is no systematic correction factor, the analyst should not rely on one set of estimates, but rather should compare results from several approaches coupled with a good working knowledge of the community's economy in order to arrive at the "best" estimate (Isserman, 1980).

Economic base models and multipliers are justified by the existence of a long-run relationship between activities of basic and nonbasic economic sectors. Because a long-run relationship is assumed, this concept is dynamic and places export-base analysis in a time series context (Engle and Granger 1991). Some past studies have employed a cross-sectional analysis of the existence of short-run and long-run multipliers (Shahidsaless, Gillis, and Shaffer 1983; Braschler 1972; McNulty 1977; Mandelbaum and Chicoine 1985; Mulligan and Kim 1991) while others either use monthly or quarterly time series data for a selected county to test for short-run and long-run multipliers (Henry and Nyankori 1981; Cook 1979; Spreen and Mulkey 1980; Giarrantani and McNelis 1980). Cross-sectional studies are static in nature and any examination of change during a single time period alone may produce misleading results.

However, when a time series approach is used, many problems arise. First, variables of interest may be nonstationary and thus require some degree of differencing (or detrending) to achieve stationarity. Moreover, in transforming the nonstationary time series into a stationary time series, valuable long-run information in the data may be lost and, therefore, theories based on long-run relationship may not be supported. Otherwise, regressions involving nonstationary variables can result in more serious problems, including spurious regression, incorrect specification, and poor model forecasting performance (Charemza and Deadman 1992).

Second, for time series data the concept of cointegration should be investigated. Cointegration implies a long-run relationship between variables with an equilibrium factor. If variables such as basic and nonbasic variables are cointegrated, their ratio will tend not to drift apart over time. Such a cointegrated relationship is important policy-wise because it is often assumed that basic and nonbasic sectors have stable long-run relationships. However, if this relationship is not stable, then policies enacted may have unintended impacts. 
In a study of the Philadelphia SMSA, Brown, Coulson, and Engle (1992) presupposed the cointegration relationship, while in a study of the Los AngelesLong Beach SMSA, Heonsoo (1994) tested the cointegration relationship as economic base theory under which various measures of base were tested. LeSage (1990) employed error correction mechanism models to forecast metropolitan employment for eight SMSA's in Ohio. Nishiyama (1997) found that economic base theory through cointegration holds strongly for the crudest definition of base, such as the assignment procedure, but not for other base definitions for the states of California, Massachusetts, and Texas.

It has been argued that small and isolated economies rather than large state and metropolitan economies may be more appropriate for export-base theories and methodologies. As Blumenfeld (1995) states: "The 'basic/non-basic ratio' is meaningful only in small and isolated economies rather than large and more complex; that is, the more 'metropolitan' the community, the less applicable is the ratio and the entire method" (p. 114). For this paper, unlike the previous studies, five rural Nevada counties will be used to investigate the use of confirmatory factor analysis, cointegration, and error correction mechanism procedures for export-base modeling. In pursuance of this objective, the paper is divided into six sections. First, a discussion of the data and study area is presented. Second, export-base theory is discussed. Third, bifurcation of employment data employing confirmatory analysis is made. Fourth, cointegration is introduced and the analysis of cointegration for multivariate systems is discussed. Fifth, the use of error correction mechanism modeling for dynamic forecasting is presented. Finally, an empirical analysis of confirmatory factor analysis, cointegration, and error correction mechanism procedures to estimate export-base activity for five rural Nevada counties is presented.

\section{DATA AND STUDY AREA}

As stated earlier, small economies, as opposed to state and large metropolitan economies, may be more appropriate for export-base analysis. This paper, as opposed to previous cointegration and error correction mechanism analyses of export-base, will be applied to five rural Nevada counties. These counties are Elko, Eureka, Lincoln, Nye, and White Pine (Figure 1). All five of these counties have been classified by the U.S. Department of Energy as impacted counties for the potential Yucca Mountain nuclear waste depository.

All five counties are nonmetropolitan counties with different characteristics. Elko County has been one of the fastest-growing counties in the state of Nevada. Population in Elko County rose from 17,269 in 1980 to 33,530 in 1990, a 94.2 percent increase. Most of Elko County's growth can be attributed to expansion in the gold mining and casino/gambling industries.

Eureka County, a much smaller county, has also realized growth in population, rising from 1,198 in 1980 to 1,547 in 1990, a 29.1 percent increase. The expansion of the Eureka County economy can be attributed to the expansion of gold mining activities. For Eureka County, the mining industry accounted for 96 
percent of total county employment. However, since most of the new mining developments have occurred in northern Eureka County where little or no housing is available, most of the job force resides in Elko County.

Lincoln County's population realized a slower growth rate through the 1980s, rising from 3,732 in 1980 to 3,775 in 1990, an increase of only 1.2 percent. As

FIGURE 1

Rural Nevada Counties Used in Analysis

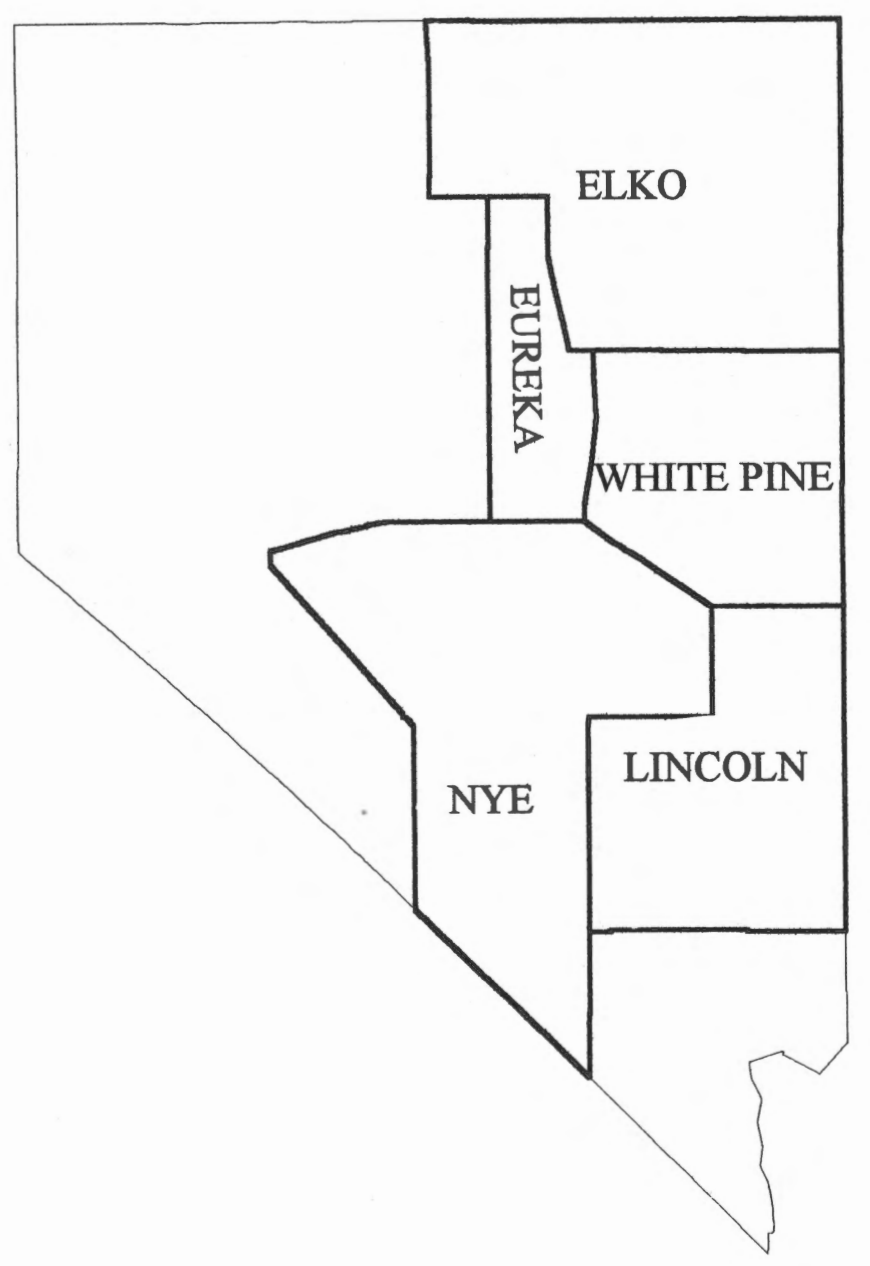

opposed to many of Nevada's rural counties, mines have closed in Lincoln County during the 1980's. The principal employer in Lincoln County is the Federal Test Site, which has experienced layoffs due to the downsizing of the U.S. military.

Nye County realized rapid population growth in the 1980s, rising from 9,048 in 1980 to 17,780 in 1990, an increase of 96.5 percent. Southern Nye County, and specifically the community of Pahrump, realized rapid population growth due to the retirement population migrating from Southern California. Pahrump also has become a bedroom community to the metropolitan community of Las Vegas. The primary employment sectors in Nye County are the mining and 
service sectors. People employed at the Nevada Test Site are employed in the service sector. The location of the potential Yucca Mountain nuclear waste dump is in Nye County.

White Pine County's population grew from 8,167 in 1980 to 9,264 in 1990, an increase of 13.4 percent. Like most of Nevada's rural economies, employment in White Pine County has primarily occurred in the mining and service sectors. The newest national park, Great Basin National Park, is located in White Pine County and may provide impetus for growth in the county's tourism industry.

One-digit SIC monthly nonagricultural employment data for the five Nevada counties and the nation were collected from January 1970 to December 1992. The one-digit SIC sectors were Mining; Construction; Manufacturing; Public Utilities; Trade, Finance, Insurance and Real Estate; Services; and Government. These data from 1970 to 1989 were used to derive export-base multipliers for the five counties. The remaining data were employed to complete the export-base analysis of forecast procedures.

\section{Export-Base Model}

The export-base model assumes that total economic activity can be divided into two distinct sectors: basic and nonbasic. The export, or basic, sector provides dollar inflows into the regional economy, which according to export-base theory generates future economic growth in the local economy. The export-base model can be expressed as:

$$
\mathrm{E}_{\mathrm{T}}=\mathrm{E}_{\mathrm{B}}+\mathrm{E}_{\mathrm{NB}} \text {, }
$$

where $E_{T}$ is total employment, $E_{B}$ is basic sector or export-generated employment, and $\mathrm{E}_{\mathrm{NB}}$ is nonbasic sector or locally generated employment.

By using time series data for $\mathrm{E}_{\mathrm{T}}$ and $\mathrm{E}_{\mathrm{B}}$, a regression estimate may be obtained by adding an error term, or:

$$
\mathrm{E}_{\mathrm{t}}=\alpha+\beta \mathrm{E}_{\mathrm{Bt}}+\mu_{\mathrm{t}} \text {. }
$$

However, when $E_{T}$ is a function of $E_{B}$, then Equation 2 has $E_{T}$ being regressed with part of itself and would blur any statistical distinction of the estimated parameter. The resulting $R^{2}$ may be spuriously large, so Equation 2 can be rewritten as:

$$
\mathrm{E}_{\mathrm{NBt}}=\alpha+\beta \mathrm{E}_{\mathrm{Bt}}+\mu_{\mathrm{t}} \text {. }
$$

The $\beta$ coefficient derives the impacts to nonbasic employment from changes in basic sector employment. Total regional employment impacts are derived by adding one to the $\beta$ coefficient and the total employment multiplier from Equation 3 becomes $(1+\beta)$.

In previous cointegration export-base studies by Heonsoo (1994) and Brown, Coulson, and Engle (1992), experiments employed Equation 2, where $\mathrm{E}_{\mathrm{T}}$ is a function of $\mathrm{E}_{\mathrm{B}}$, for cointegration and dynamic export-base analysis. For this 
paper, the export-base model shown in Equation 3 will be employed, where $\mathrm{E}_{\mathrm{NB}}$ and $E_{B}$ are tested for cointegration and dynamic export-base analysis.

\section{DEFINITION OF EXPORT-BASE}

One of the most contentious issues facing the development of an exportbase model is the identification of a region's basic or export activity. The economic base model is predicated upon the bifurcation of regional economic activity into at least two distinct sectors, export, or basic, sector and nonexport, or nonbasic, sector. Data for development of export-base activity is usually unobtainable, except at a high cost, at the regional, state, and county level. Because of the high cost, potential selection bias, and accuracy errors from respondents, nonsurvey techniques for identifying basic or export activity have been adopted by many regional scientists and economic development practitioners. Over time, numerous studies have appeared in the literature devoted to the formulation and refinement of competing nonsurvey techniques. Richardson (1985) and Isserman (1980) have provided an excellent review and critique of nonsurvey techniques, such as the assignment, location quotient, minimum requirements, and Mathur-Rosen techniques. For this paper, three nonsurvey procedures were employed to derive five different basic sector employment estimates. These three nonsurvey procedures were the assignment, location quotient, and minimum requirements procedures.

BASE 1 and BASE 2 bifurcation of county employment were derived by employing assignment procedures. Under assignment procedures, employment within broad employment categories is assigned totally to the basic or nonbasic sector. For BASE 1, employment in the Mining, Construction, and Manufacturing sectors was aggregated as basic sector employment. For BASE 2, only employment in the Mining sector constituted basic sector employment.

Location quotient procedures do not assume that all of an industry's employment must be entirely basic or nonbasic, but rather use secondary information sources such as national employment to estimate bifurcation of total employment. Location quotient procedures employed in this paper follow a time series version developed by LeSage and Reed (1989), or may be stated as:

$$
\mathrm{LQ}_{\mathrm{irt}}=\frac{\mathrm{E}_{\mathrm{irt}} / \mathrm{E}_{\mathrm{rt}}}{\mathrm{E}_{\mathrm{int}} / \mathrm{E}_{\mathrm{nt}}}
$$

where:

$E_{i r t}$ is employment in sector $i$ in region $r$ at time period $t$;

$E_{r t}$ is total employment in region $r$ at time period $t$;

$E_{\text {int }}$ is national employment in sector $i$ at time period $t$;

$E_{n t}$ is total national employment at time period $t$; and

$\mathrm{LQ}_{\text {irt }}$ is location quotient for sector $\mathrm{i}$ in region $\mathrm{r}$ at time period $\mathrm{t}$. 
After calculating location quotient values, if $\mathrm{LQ}_{\text {irt }}$ is greater than one, the region is said to be producing more than the expected amount of output in that sector, hence the excess is classified as that portion of industry $i$ that is basic employment. Therefore, the basic employment for region $r$ in sector $i$, or $\mathrm{EB}_{\mathrm{irt}}$ can be given by:

$$
E_{\text {Birt }}=\frac{L Q_{\text {irt }}-1}{L Q_{\text {irt }}} E_{\text {irt }},
$$

if $L_{\text {irt }}>1$. The sum of these $\mathrm{EB}_{\text {irt }}$ 's across all sectors then creates BASE 3.

Location quotient procedures, however, have been criticized for underestimating export or basic sector employment (Tiebout 1962). BASE 4 attempts to address this criticism by assigning total sectoral employment to basic sector employment if the sector's calculated location quotient value is greater than one. This procedure, however, has been criticized for overestimating export or basic sector employment because this procedure includes sectors that may in part be serving the local economy (Richardson 1985).

The final procedure, or BASE 5, employed the minimum requirements approach. The main difference between the location quotient approach and minimum requirements is that the county's employment structure is compared to a sample of similarly sized counties rather than the nation as a whole. For each industry $i$, the county within each size class that has a minimum share of its employment devoted to industry $i$ is identified. Every other county within the size class is assumed to produce for export, with its export activity consisting of the difference between an industry's share of employment in the county and the industry's share in the county where the minimum share occurred.

Moore (1975) replicated an earlier study by Ullman and Darcy (1960) by regressing minimum employment share for a selected city against median population of a given city size using 1970 cross-sectional data. The relationship is stated as:

$$
\mathrm{E}_{\mathrm{im}}=\mathrm{a}+\mathrm{b} \log \mathrm{POP},
$$

where $E_{i m}$ is the minimum employment or nonbasic employment for sector $i$ and POP is the population.

Using regression results of Equation 6 by Moore (1975), minimum requirements for each sector were calculated. Excess employment above the minimum requirement was designated as basic sector employment. Nonbasic employment for a given sector i was calculated as the minimum requirement in Equation 6 . Summation of sectoral basic and nonbasic employment yields total county basic and nonbasic sector employment.

However, the minimum requirements procedure has been criticized as fundamentally flawed (Pratt 1968). The minimum requirements procedure assumes that each county, except the county with the minimum share, produces for export. Therefore counties will satisfy local demands for a given good or 
service from local production and no importing of a given good or service exists for internal consumption.

\section{INDICATOR MODEL SPECIFICATION}

In estimating export-base multipliers as in Equation 3, the calculation of basic and nonbasic employment is crucial. However, export or basic employment activity is an unobservable variable and procedures discussed in the preceding section are imperfect bifurcations of county employment. Although not perfect, these observations, or proxies, might provide some indication of the unobservable latent variable, or basic employment. Thus, to derive export or basic activity, the modeling approach should address two problems in constructing the unobservable variable: (1) how to determine the appropriate weights for each indicator; and (2) how to determine the amount of noise in each indicator.

Bollen (1989) has proposed that confirmatory factor analysis (CFA) can be used to specify a relationship among a set of indicators and the unobserved latent variable $x$. CFA combines the weights of the indicators as well as the errors of each indicator to derive values of the latent variable, which is basic sector employment. As Bollen (1989) shows, the influence of these different observed indicators can be stated as:

$$
\left[\begin{array}{c}
\mathrm{x}_{1 \mathrm{t}} \\
\mathrm{x}_{2 \mathrm{t}} \\
\cdot \\
\cdot \\
\mathrm{x}_{\mathrm{kt}}
\end{array}\right]=\left[\begin{array}{c}
\lambda_{1} \\
\lambda_{2} \\
\cdot \\
\lambda_{\mathrm{k}}
\end{array}\right] \xi_{\mathrm{t}}+\left[\begin{array}{c}
\varepsilon_{1 \mathrm{t}} \\
\varepsilon_{2 \mathrm{t}} \\
\cdot \\
\cdot \\
\varepsilon_{\mathrm{kt}}
\end{array}\right] .
$$

The $k$ variables, $x_{1 t^{\prime}} \ldots, x_{k t}$ serve as indicators of the latent variable $\xi$. The elements of $\lambda=\left(\lambda_{1}, \ldots, \lambda_{k}\right)$ are factor loadings, or proportionalities between the different indicators and the unobserved variable basic employment. None of the indicators are perfect but are rather observed as influencing $\xi$ with errors $\varepsilon_{1 t}, \ldots, \varepsilon_{\mathrm{kt}}$ such that $\mathrm{E}(\varepsilon)=0$ and $\mathrm{E}\left(\varepsilon \varepsilon^{\prime}\right)=\mathrm{V}$. The closeness of the relationship between any indicator $\mathrm{x}_{\mathrm{it}}$ and $\xi$ is proportional to $\lambda_{\mathrm{i}}$ and the variance of $\varepsilon_{\mathrm{it}}$. Typically, one of the loadings is set to a value of one to provide a means for identifying the latent factor's scale. The $\varepsilon_{\mathrm{t}}$ vector recognizes that none of the indicators is a perfect proxy for the latent variable and the magnitudes of the diagonal elements of $\mathrm{V}$ relative to the 
corresponding diagonal elements of $S$ (where $S=T^{-1} X^{\prime} X$ ) provide a means for assessing the degree of association or commonality between the latent factor and its indicators.

Assuming that the vectors in $X$ have zero means, then estimation of Equation 7 is accomplished by trying to equate the second moment of the vector on the left-hand side to the second moments of the vectors on the right-hand side for all observations. Letting $\Phi$ denote the variance of $\xi$, this latter term is:

$$
\Sigma=\lambda \Phi \lambda^{\prime}+\mathrm{V},
$$

which is equated to the sample moment matrix $S$. The unknowns to be estimated are the elements of $\lambda$, the (diagonal) elements of $V$ and $\Phi$. If these parameters are denoted by $\theta$ and if disturbances are assumed to be normally distributed, maximum likelihood parameter estimates can be obtained by maximizing:

$$
\mathrm{L}=-\left(\frac{\mathrm{T}}{2}\right) \ln \left|\sum(\theta)\right|-\left(\frac{\mathrm{T}}{2}\right) \operatorname{trace}\left(\mathrm{S} \sum(\theta)^{-1}\right)
$$

with respect to $\theta$ (Bollen 1989).

\section{COINTEGRATION AND EXPORT-BASE}

Most studies that have used CFA have been cross-sectional studies. A study by Shonkwiler and Moss (1993), however, employed time series data to estimate farm financial stress. In the Shonkwiler and Moss (1993) study, the time series data were not tested for stationarity, which may influence the resulting indicator.

If a time series is not stationary, the data will exhibit trends. Nelson and Plosser (1982) indicated that most national aggregate data time series are nonstationary. More recently, Schmidt (1995) and Engle and Issler (1995) found that regional time series data and sector aggregates are nonstationary also. Nelson and Plosser (1982) stressed the importance of identifying stationarity of a time series not only from a statistical standpoint but also from a policy perspective. For example, if variables for basic and nonbasic employment were not cointegrated, then policies that assume a stable long-term relationship between basic and nonbasic employment would be incorrect.

One of the statistical procedures to investigate stationarity of a time series is the Augmented Dickey-Fuller (ADF) test (Dickey and Fuller 1979). The ADF tests the unit root as expressed:

$$
\begin{aligned}
& \Delta \mathrm{E}_{\mathrm{NBt}}=\alpha_{1}+\delta \mathrm{E}_{\mathrm{NBt}-1}+\sum_{\mathrm{i}=1}^{\mathrm{n}} \varphi_{\mathrm{i}} \Delta \mathrm{E}_{\mathrm{NBt}-1}+\varepsilon_{1 \mathrm{t}} \\
& \Delta \mathrm{E}_{\mathrm{Bt}}=\alpha_{2}+\delta \mathrm{E}_{\mathrm{Bt}-1}+\sum_{\mathrm{i}=1}^{\mathrm{n}} \beta_{\mathrm{i}} \Delta \mathrm{E}_{\mathrm{Bt}-1}+\varepsilon_{2 \mathrm{t}}
\end{aligned}
$$

where $\mathrm{n}=12$ for monthly time series data to allow a good approximation to the $\operatorname{ARMA}(\mathrm{p}, \mathrm{q})$ process $\mathrm{U}_{\mathrm{t}}$, so that $\varepsilon_{1 \mathrm{t}}$ and $\varepsilon_{2 \mathrm{t}}$ are white noise. Also, $\delta=\mathrm{p}-1$ so that the 
null is transformed into a zero restriction on the coefficient of the lagged dependent variable.

In the case of Equations 10 and 11, the null hypothesis is nonstationarity. If a series is $\mathrm{I}(1)$, this implies that the data have achieved stationarity after first differencing and suggests the presence of a unit root. If two series have unit roots, they are candidates for cointegration.

According to Granger (1986), if two variables such as $\mathrm{E}_{\mathrm{Bt}}$ and $\mathrm{E}_{\mathrm{NBt}}$ are individually $\mathrm{I}(1)$, the concern is whether there exists a parameter a such that the difference is stationary:

$$
\mathrm{Z}_{\mathrm{t}}=\mathrm{E}_{\mathrm{NBt}}-\alpha \mathrm{E}_{\mathrm{Bt}} \text {. }
$$

If so, the variables $E_{B t}$ and $E_{N B t}$ are said to be cointegrated, $C(1,1)$, with $\alpha$ designated as the cointegrating parameter. Cointegration implies a long-run relationship between variables with an equilibrium error represented by $Z_{t^{*}}$. This means that the two variables $\mathrm{E}_{\mathrm{NBt}}$ and $\mathrm{E}_{\mathrm{Bt}}$ do not drift too far apart from each other over time. Cointegration of these two variables reinforces the export-base multiplier postulate of a constant, long-run relationship between basic and nonbasic employment.

If nonbasic employment and basic employment are not cointegrated, that is, $Z_{t}=E_{N B t}-\alpha E_{B t}$ is $I(1)$, they can drift apart from one another as time goes on, which implies that there is no long-run equilibrium relationship between the two variables. Consequently, an OLS regression of these two variables would be a spurious regression primarily because the standard errors are highly misleading (Granger and Newbold 1974). Also, the regression coefficients would prove not to be consistent estimates of the population parameters, and the sample residuals of the linear regression will not be stationary. Given these deficiencies, if export-base models using time series data have not been tested for cointegration, the resultant regression may yield no meaningful statistical inference.

Employing the Engle and Granger (1987) two-step procedure requires the test to be based on the residuals of the OLS regression of nonbasic employment on basic employment. An auxiliary regression is run using the regression residuals and employing the Dickey-Fuller and ADF procedures. The five basic employment definition procedures were used as regressors, with nonbasic employment being the regressand in the cointegrated system.

Testing for cointegration entails testing the order of the error in the relationship. Thus the hypothesis to test for the existence of cointegration can be formulated as:

$$
\begin{aligned}
& \mathrm{H}_{0}: \hat{\varepsilon}_{\mathrm{t}}=\mathrm{E}_{\mathrm{NBt}}-\hat{\alpha} \mathrm{E}_{\mathrm{Bt}} \text { is } \mathrm{I}(1) \\
& \mathrm{H}_{1}: \hat{\varepsilon}_{\mathrm{t}}=\mathrm{E}_{\mathrm{NBt}}-\hat{\alpha} \mathrm{E}_{\mathrm{Bt}} \text { is } \mathrm{I}(0),
\end{aligned}
$$

which implies a test for stationarity on the residuals of the cointegration regression. 


\section{ERROR CORRECTION MECHANISM MODEL AND EXPORT-BASE}

Error correction mechanism (ECM) models introduced by Sargan (1964), Phillips (1957), and Hendry and Anderson (1977) have realized popular application especially in the macroeconomics area. Because of cointegration research by Granger (1983) and Engle and Granger (1987), ECM models have realized expanded popularity and use. The representation theorem proven by Granger (1983) has increased the importance of ECM in cointegration research. The representation theorem states that if two variables are integrated of order one and cointegrated, these variables can be modeled through an ECM framework. The ECM specification captures the short-run dynamics that relate the change in total employment to past equilibrium errors, as well as to past changes in basic employment. ECM uses the criterion that a proportion of disequilibrium from one period is corrected in the following period. ECM specification allows an alternative test of the existence of equilibrium imposed by theory and it seems likely that such tests will on occasion be more powerful than simple cointegration tests. Engle and Yoo (1987) provide theoretical derivation to support the superior forecasting ability of ECM models over unrestricted VAR models. Although ECM models have been rigorously applied for macroeconomic forecasting, ECM models have not as of yet been applied at the nonmetropolitan level.

Following the Granger Representation Theorem (Granger 1983; Engle and Granger 1987), which proves if $\mathrm{E}_{\mathrm{NBt}}$ and $\mathrm{E}_{\mathrm{Bt}}$ are $\mathrm{I}(1)$ and are cointegrated, there always exists a generating mechanism for these variables, which is the error correction mechanism shown below:

$$
\begin{aligned}
& \Delta \mathrm{E}_{\mathrm{Bt}}=\mathrm{D}_{1}+\gamma_{1} \mathrm{Z}_{\mathrm{t}-1}+\sum_{\mathrm{j}=1}^{\mathrm{m}} \beta_{\mathrm{j}} \Delta \mathrm{E}_{\mathrm{Bt}-\mathrm{j}}+\sum_{\mathrm{j}=1}^{\mathrm{m}} \alpha_{\mathrm{j}} \Delta \mathrm{E}_{\mathrm{NBt}-\mathrm{j}}+\varepsilon_{\mathrm{t}}^{\prime} \\
& \Delta \mathrm{E}_{\mathrm{NBt}}=\mathrm{D}_{2}+\gamma_{2} \mathrm{Z}_{\mathrm{t}-1}+\sum_{\mathrm{j}=1}^{\mathrm{m}} \lambda_{\mathrm{j}} \Delta \mathrm{E}_{\mathrm{Bt}-\mathrm{j}}+\sum_{\mathrm{j}=1}^{\mathrm{m}} \Phi_{\mathrm{j}} \Delta \mathrm{E}_{\mathrm{NBt}-\mathrm{j}}+\varepsilon_{\mathrm{t}}^{\prime \prime},
\end{aligned}
$$

where $\gamma_{1}, \gamma_{2}, \beta_{\mathrm{j}}, \alpha_{\mathrm{j}}, \lambda_{\mathrm{j}}$, and $\Phi_{\mathrm{j}}$ are the parameters to be estimated, $\gamma_{1}, \gamma_{2} \neq 0$, and $\varepsilon_{\mathrm{t}}^{\prime}$ and $\varepsilon^{\prime \prime}$ are finite-order moving averages.

The error correction term $Z_{t-1}$ must at least enter one of the equations of the model in the presence of cointegration and has important implications as to Granger (1969) causality testing. A test of cointegration should be carried out before causality tests in order to determine if cointegration exists.

Granger causality will be employed to test the assumption of export-base theory that export or basic sector activities through export sales initiate local economic growth. This unidirectional influence as to economic growth has been questioned in numerous studies (LeSage and Reed 1989; Krikelas 1991; Polzin et al. 1988).

If cointegration exists between basic and nonbasic employment, then Granger causality is a precursor to forecasting. The causal direction suggests that one variable will help forecast the other. Causal relation between basic and non- 
basic employment carries a natural forecasting implication: that is, past values of nonbasic employment as well as past and current basic employment should help to predict or forecast nonbasic employment. Given that basic and nonbasic employment time series generated by the method of decomposition are consistent with export-base theory, the forecasting ability of a vector autoregressive exportbase model should be enhanced. The ECM forecasting model can be expressed as:

$$
\Delta \mathrm{E}_{\mathrm{NBt}}=\lambda_{1}+\gamma_{1} \mathrm{Z}_{\mathrm{t}-1}+\sum_{\mathrm{i}=1}^{\mathrm{n}} \beta_{\mathrm{j}} \Delta \mathrm{E}_{\mathrm{NBt}-1}+\sum_{\mathrm{i}=0}^{\mathrm{n}} \alpha_{\mathrm{i}} \Delta \mathrm{E}_{\mathrm{Bt}-1}+\varepsilon_{\mathrm{t}}
$$

where $\beta_{\mathrm{j}}$ and $\alpha_{\mathrm{i}}$ represent short-run (differences) and $\gamma_{1}$ represents long-run (levels) adjustment processes.

\section{RESULTS}

The empirical results are shown in four sections. First, the CFA procedure to bifurcate total employment into basic and nonbasic employment is presented and basic and nonbasic employment are tested for stationarity and cointegration. Second, from the cointegrated series, the export-base ECM models are presented. Third, causal structure of the export-base model is tested using Granger causality procedures. Finally, an evaluation of the forecasting abilities of the export-base model is initiated at the end of the estimation period of January 1990 to December 1992.

\section{Stationarity, CFA, and Cointegration}

\section{TABLE 1}

Augmented Dickey-Fuller Tests for Stationarity of Time Series Data for Basic Employment Estimates

\begin{tabular}{lccccc}
\hline \multirow{2}{*}{ County } & \multicolumn{2}{c}{ BASE Definition } & \multicolumn{2}{c}{} \\
\hline Elko & BASE 1 & BASE 2 & BASE 3 & BASE 4 & BASE 5 \\
\multirow{2}{*}{ Eureka } & $-3.06^{*}$ & -2.78 & -2.12 & -0.861 & -1.45 \\
& $(1.93) \mathrm{a}$ & $(-0.65)$ & $(-1.41)$ & $(-0.26)$ & $(-1.48)$ \\
Lincoln & -1.66 & -2.38 & -1.62 & -1.46 & -1.64 \\
& $(-1.98)$ & $(0.70)$ & $(0.34)$ & $(-0.77)$ & $(-0.10)$ \\
Nye & -1.99 & -1.83 & -1.34 & -1.44 & -1.04 \\
& $(-0.53)$ & $(-0.32)$ & $(-0.87)$ & $(0.32)$ & $(-0.76)$ \\
White Pine & -2.67 & -2.54 & -2.84 & -2.86 & -3.07 \\
& $(-0.55)$ & $(-1.20)$ & $(-0.01)$ & $(-0.10)$ & $(-0.12)$ \\
& -2.22 & -2.13 & -1.89 & -2.71 & -2.44 \\
& $(0.01)$ & $(-0.63)$ & $(0.16)$ & $(-1.10)$ & $(-0.71)$ \\
\hline
\end{tabular}

*Value indicates stationarity of variable or levels.

a Numbers in parentheses are calculated $t$-values, which represent a test for first-order autoregressive disturbances for each equation.

BASE 1 is assignment procedure with basic employment, all employment in the Mining, Manufacturing, and Construction sectors.

BASE 2 is assignment procedure with basic employment, all employment in the Mining sector.

BASE 3 is the location quotient procedure where calculated sectoral excess employment is allocated as basic sector. BASE 4 is the location quotient procedure where all sectoral employment is allocated to basic employment if $\mathrm{LQ}_{\text {irt }}>1$.

BASE 5 is where sectoral employment is allocated to basic or nonbasic sector through the minimum requirements procedure.

Table 1 shows the results of the ADF test statistic derived from Equation 10, including the drift term. From Table 1, only one of the 25 procedures for estimating basic sector employment (BASE 4 for White Pine County) had a significant 
$t$-value to reject the null hypothesis of nonstationarity at the $5 \%$ level. Therefore, given the nonstationarity of the time series data, the data was transformed into stationary process by taking the log differences of the data. From the stationarity data set, the indicator model was derived for the five counties.

TABLE 2

Estimates of the Factor Analytic Model for Basic Employment for Elko, Eureka, Lincoln, Nye, and White Pine Counties, Nevada

\begin{tabular}{|c|c|c|c|c|c|}
\hline \multirow[b]{2}{*}{ Parameter } & \multicolumn{4}{|c|}{ Maximum Likelihood Estimates for Counties } & \multirow[b]{2}{*}{ White Pine } \\
\hline & Elko & Eureka & Lincoln & Nye & \\
\hline$\overline{\lambda_{1}}$ & 1.00000 & 1.00000 & 1.0000 & 0.26435 & 1.00000 \\
\hline & $(-)^{*}$ & $(-)$ & $(-)$ & $(0.07351)$ & $(-)$ \\
\hline$\lambda_{2}$ & 0.91241 & 0.68619 & 0.89424 & 0.31509 & 1.08328 \\
\hline & $(0.09764)$ & $(0.03552)$ & $(0.08503)$ & $(0.08927)$ & $(0.03876)$ \\
\hline$\lambda_{3}$ & $\begin{array}{c}0.32956 \\
(0.03251)\end{array}$ & $\begin{array}{c}0.89244 \\
(0.03074)\end{array}$ & $\begin{array}{c}0.76543 \\
(0.19945)\end{array}$ & 1.0000 & 0.52862 \\
\hline$\lambda_{4}$ & 0.47213 & 0.85439 & 0.40228 & 0.93569 & $\begin{array}{l}(0.0 \angle 464) \\
-0.10956\end{array}$ \\
\hline & $(0.07385)$ & $(0.05554)$ & $(0.05556)$ & $(0.01364)$ & $(0.05240)$ \\
\hline$\lambda_{5}$ & 0.35386 & 0.88972 & 0.51283 & 0.73579 & 0.32486 \\
\hline$\varphi$ & $0.00676)$ & $\begin{array}{c}(0.03281) \\
0.00283\end{array}$ & $\begin{array}{c}(0.12794) \\
0.00801\end{array}$ & $\begin{array}{c}(0.01410) \\
0.00324\end{array}$ & (0.01062) \\
\hline & $(0.00092)$ & $(0.00029)$ & $(0.00272)$ & $(0.00028)$ & $(0.00144)$ \\
\hline $\mathrm{V}_{11}$ & 0.00291 & 0.00053 & 0.03569 & 0.00474 & -0.00046 \\
\hline & $(0.00053)$ & $(0.00006)$ & $(0.00345)$ & $(0.00039)$ & $(0.00025)$ \\
\hline $\mathrm{V}_{22}$ & 0.00843 & 0.00068 & 0.04875 & 0.00697 & 0.00638 \\
\hline $\mathrm{V}_{\mathrm{H}}$ & $(0.00088)$ & $(0.00006)$ & $(0.00430)$ & $(0.00059)$ & $(0.00058)$ \\
\hline$v_{33}$ & $\begin{array}{c}0.00071 \\
(0.00009)\end{array}$ & $\begin{array}{c}0.00016 \\
(0.00005)\end{array}$ & $\begin{array}{l}-0.00131 \\
(0.001005)\end{array}$ & $\begin{array}{c}0.00009 \\
(0.00001)\end{array}$ & $\begin{array}{c}0.00099 \\
(0.00015)\end{array}$ \\
\hline $\mathrm{V}_{44}$ & 0.00902 & 0.00197 & 0.00391 & 0.00008 & 0.01327 \\
\hline & $(0.00078)$ & $(0.00017)$ & $(0.00042)$ & $(0.00001)$ & $(0.00113)$ \\
\hline $\mathrm{V}_{55}$ & 0.00010 & 0.00014 & -0.00043 & 0.00012 & 0.00047 \\
\hline & $(0.00007)$ & $(0.00006)$ & $(0.00043)$ & $(0.00001)$ & $(0.00005)$ \\
\hline $\mathrm{V}_{21}$ & - & - & $\begin{array}{l}0.03125 \\
(0.00348)\end{array}$ & 0.00481 & \\
\hline $\mathrm{V}_{31}$ & - & - & -0.00187 & & -0.00157 \\
\hline$V_{42}$ & $\ldots$ & - & $(-0.10000)$ & 200012 & (0.00016) \\
\hline & & & & $(0.00003)$ & \\
\hline$V_{43}$ & & & & & 0.00183 \\
\hline$V_{51}$ & 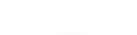 & 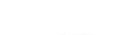 & 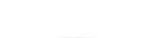 & ค คด०17 & $(0.00033)$ \\
\hline 51 & & & & $(0.00003)$ & - \\
\hline$V_{52}$ & -0.00050 & -0.00024 & - & - & - \\
\hline$V_{52}$ & $\begin{array}{c}(0.00012) \\
0.00016\end{array}$ & $\begin{array}{l}(0.00004) \\
-0.00019\end{array}$ & -0.00139 & - & -000532 \\
\hline & (0.00007) & $(0.00004)$ & $(0.00066)$ & & $(0.00076)$ \\
\hline Goodness of Fit: & & & & & \\
\hline Chi-Square** & 2.87649 & 6.383 & 0.61533 & 1.52345 & 5.01395 \\
\hline Degrees of Freedom & 3 & 2 & 2 & 2 & 2 \\
\hline
\end{tabular}

*Calculated standard errors are in parentheses.

**Calculated chi-square values fail to reject hypothesis. Therefore, the indicator model fits data for the county.

CFA parameter estimates from the maximization of the log-likelihood function (Equation 9) for the five counties are shown in Table 2. The coefficients $\lambda_{1}$ through $\lambda_{5}$ and $v_{11}$ and $v_{55}$ correspond to the five basic employment sector indicators of BASE 1 through BASE 5. $\Phi$ is a variance of the latent variable. The $\lambda_{1}$ coefficient for Elko, Eureka, Lincoln, and White Pine Counties was normalized to unity to establish a scale for $\xi$. For Nye County, the $\lambda_{3}$ coefficient was normalized to unity to establish a scale for $\xi$. Also, possible covariance between the noise in 
BASE 1 and BASE 2, BASE 1 and BASE 3, BASE 2 and BASE 4, BASE 3 and BASE 4, BASE 1 and BASE 5, BASE 2 and BASE 5, and BASE 3 and BASE 5 is accounted for by assuming $\mathrm{V}_{12}=\mathrm{V}_{21}, \mathrm{~V}_{13}=\mathrm{V}_{31}, \mathrm{~V}_{24}=\mathrm{V}_{42}, \mathrm{~V}_{34}=\mathrm{V}_{43}, \mathrm{~V}_{15}=\mathrm{V}_{51}, \mathrm{~V}_{25}=\mathrm{V}_{52}$, and $V_{35}=V_{53}$. With the exception of White Pine County, each factor-loading coefficient is positive.

In order to assess the validity of the estimated model for each county, a test of overidentifying restrictions implied by the specification was performed. The sample moment $\mathrm{S}$ matrix has fifteen unique elements (fourteen in the case of White Pine County) of which twelve are estimated, thus there are three overidentifying restrictions. A likelihood ratio test of whether these restrictions are consistent with the data generation process (Bollen 1989) yields the test statistics reported at the bottom of Table 2. Since the calculated test statistic does not exceed a chi-squared critical value at the $5 \%$ level, the overidentifying restrictions cannot be rejected. Therefore, it is concluded that for each county the indicator model results found in Table 2 appropriately fit the data.

With regards to the degree of association between the individual indicators and the latent factor, the square correlation or communality is given by:

$$
\mathrm{r}_{\mathrm{i}}^{2}=1-\frac{\hat{\mathrm{V}}_{\mathrm{ii}}}{\Sigma_{\mathrm{ii}}}
$$

From Table 3, the calculated values for Elko County BASE 1 through BASE 5 are $0.69,0.40,0.50,0.14$, and 0.89 . This suggests that the (marginal) relative importance of the indicators in decreasing order is BASE 5 (minimum requirements procedure); BASE 1 (assignment procedure where all Mining, Manufacturing, and Construction sectors are allocated to basic); BASE 3 (excess location quotient); BASE 2 (assignment procedure where only Mining sector employment is allocated to basic); and BASE 4 (location quotient procedure 2 or all sector employment allocated to basic sector if $L_{\mathrm{irt}}>1$ ). Eureka County follows the same order as Elko.

\section{TABLE 3}

Degree of Association Between Individual Indicators and the Latent Variables for Elko, Eureka, Lincoln, Nye, and White Pine Counties, Nevada

\begin{tabular}{llcccc}
\hline Indicator & Elko & Eureka & Lounties & Nye & White Pine \\
\hline BASE 1 & 0.69 & 0.84 & 0.27 & 0.05 & 1.00 \\
BASE 2 & 0.40 & 0.66 & 0.18 & 0.04 & 0.76 \\
BASE 3 & 0.50 & 0.93 & 0.77 & 0.97 & 0.83 \\
BASE 4 & 0.14 & 0.51 & 0.41 & 0.97 & 0.02 \\
BASE 5 & 0.89 & 0.94 & 0.73 & 0.93 & 0.79 \\
\hline
\end{tabular}

BASE 1 is assignment procedure with basic employment, all employment in the Mining, Manufacturing, and Construction sectors.

BASE 2 is assignment procedure with basic employment, all employment in the Mining sector.

BASE 3 is the location quotient procedure where calculated sectoral excess employment is allocated as basic employment.

BASE 4 is the location quotient procedure where all sectoral employment is allocated to basic employment if $\mathrm{LQ}_{\text {irt }}>1$.

BASE 5 is when sectoral employment is allocated to basic or nonbasic sector through the minimum requirements procedure. 
Given factor loadings and the estimated variances, unbiased estimates of the latent basic variable series can be constructed:

$$
\xi_{t}=\left(\hat{\lambda}^{\prime} \hat{\Sigma}^{-1} \hat{\lambda}\right)^{-1} \hat{\lambda}^{\prime} \hat{\Sigma}^{-1} X_{t}
$$

where $\hat{\Sigma}$ is the diagonal variance-covariance matrix of the errors from Equation 8, $\hat{\lambda}$ is the vector of factor loadings, and $X_{t}$ are the indicators. Assuming total employment is known and is without error, estimates of latent nonbasic employment are derived by subtracting the predicted latent basic employment series $\xi_{t}$ from total employment. Cointegration procedures are again employed to examine if both series exhibit time series properties and, more importantly, to test the proposition that estimated latent basic employment series can predict future values of nonbasic employment.

If basic and nonbasic employment are not cointegrated, this suggests that the basic and nonbasic employment sectors do not tend to move together and, therefore, a long-run equilibrium does not exist. Hence, changes in basic employment apparently impact nonbasic employment unevenly leading to real gains and losses that do not vanish over time. Table 4 shows the test of the estimated series for stationarity. Evidence supports the claim that the two series follow a unit root process.

\section{TABLE 4}

Unit Root Tests for the Time Series Variables

\begin{tabular}{lcc}
\hline & \multicolumn{2}{c}{ Unit Root Test } \\
County & Basic Employment & Nonbasic Employment \\
\hline Elko & -0.29 & -1.99 \\
Eureka & -1.52 & -1.57 \\
Lincoln & -1.79 & -1.66 \\
Nye & -2.12 & -2.58 \\
White Pine & -1.99 & -2.65 \\
\hline
\end{tabular}

Critical Value of the ADF Test at $5 \%$ level of significance is given as -3.44 .

Table 5 shows the intercept, the slope coefficient (or long-run indirect multiplier), and the Dickey-Fuller test of residuals for the model in equation (3). If cointegration can be found between the two variables, the results imply acceptance of the definition of a long-run relationship between basic and nonbasic employment. For all counties, the cointegration statistic is significant indicating cointegration among basic and nonbasic sectors for all counties. From Table 5, the long-run indirect multiplier for Nye County is 0.498 . This means that when basic sector employment in Nye County increases by one job, the long-run indirect nonbasic sector employment impact to Nye County is 0.498 jobs.

Park (1970) argues that the traditional multiplier indicates the total change in employment rather than in the nonbasic sector above. Therefore, to derive total impacts to an economy from a change in basic sector employment, one is added to the estimated coefficient. Therefore the long-run total multiplier for Nye County is 1.498. This means that for every one-unit change in basic sector employment in Nye County, total Nye County employment increases by 1.498 employees. 
TABLE 5

Indirect Long-Run Multipliers and Cointegration Test Results

\begin{tabular}{lccc}
\hline County & $\begin{array}{c}\text { Intercept } \\
\text { Estimate }\end{array}$ & $\begin{array}{c}\text { Parameter } \\
\text { Test Statistic * }\end{array}$ & Cointegration \\
\hline Elko & 6264.4 & 0.834 & -4.09 \\
Eureka & 302.91 & 0.582 & -4.41 \\
Lincoln & 789.81 & 1.486 & -2.89 \\
Nye & 2060.9 & 0.498 & -4.56 \\
White Pine & 896.5 & 1.240 & -3.20 \\
\hline
\end{tabular}

${ }^{*}$ Critical value of test on residuals of the cointegrating regression is given as -2.88 .

\section{Export-Base ECM Model}

Table 6 shows the ECM model for the five rural Nevada counties. The model estimation was derived from sample data from January 1970 to December 1989.

The ECM has the special advantage of separating the long-run and the short-run responses. While the coefficients estimated using the cointegrating regression represent the long-run multipliers, the information contained in the ECM specification is twofold. First, the error correction term $Z_{t-1}$ displays information pertaining to the adjustment that a process makes to a deviation from a long-run equilibrium. Hence, the estimated coefficients of this parameter represent a mechanism for short-run adjustment of a dependent variable to the associated disequilibrium with respect to the exogenous variable in a previous time period. Second, the estimated coefficients on the lagged differences of both series measure the short-term (changes) adjustment processes; hence, these could be considered as multiplier accelerators.

TABLE 6

Export-Base ECM Estimates for Five Counties

Elko County:

$\Delta \mathrm{E}_{\mathrm{NBt}}=12.586-0.026 \mathrm{Z}_{\mathrm{t}-1}-1.23 \Delta \mathrm{E}_{\mathrm{Bt}-1}-0.06 \Delta \mathrm{E}_{\mathrm{Bt}-2}+0.48 \Delta \mathrm{E}_{\mathrm{NBt}-1}+0.056 \Delta \mathrm{E}_{\mathrm{NBt}-2}$

$$
\begin{aligned}
& \begin{array}{llll}
(1.20) & \left(-3.062^{*}\right) & \left(-5.22^{*}\right) & (-0.27)
\end{array} \\
& \hat{\rho}=-0.00034 \quad R^{2}=0.3150
\end{aligned}
$$

LM (autocorrelation) $\chi^{2}(4)=0.08$

$$
\begin{aligned}
\Delta \mathrm{E}_{\mathrm{Bt}}= & 5.0225+0.0025 \mathrm{Z}_{\mathrm{t}-1}+0.57 \Delta \mathrm{E}_{\mathrm{Bt}-1}-0.08 \Delta \mathrm{E}_{\mathrm{Bt}-2}+0.21 \Delta \mathrm{E}_{\mathrm{NBt}-1}-0.0048 \Delta \mathrm{E}_{\mathrm{NBt}-2} \\
& \left(1.99^{*}\right) \quad\left(2.4^{*}\right) \\
& \left.\hat{\rho}=-0.0086 \quad \mathrm{R}^{2}=0.08^{*}\right) \quad\left(-2.25^{*}\right) \quad(0.78)
\end{aligned}
$$

LM (autocorrelation) $\chi^{2}(4)=2.16$ 


\section{Eureka County:}

$\Delta \mathrm{E}_{\mathrm{NBt}}=2.02-0.055 \mathrm{Z}_{\mathrm{t}-1}-0.245 \Delta \mathrm{E}_{\mathrm{Bt}-1}-0.39 \Delta \mathrm{E}_{\mathrm{Bt}-2}+0.14 \Delta \mathrm{E}_{\mathrm{NBt}-1}+0.15 \Delta \mathrm{E}_{\mathrm{NBt}-2}$

$$
\begin{aligned}
& (1.6) \quad\left(4.214^{*}\right) \quad\left(2.018^{*}\right) \quad\left(-3.19^{*}\right) \quad\left(2.36^{*}\right) \\
& \hat{\rho}=-0.01309 \quad \mathrm{R}^{2}=0.092
\end{aligned}
$$

LM (autocorrelation) $\chi^{2}(4)=5.81$

$$
\begin{aligned}
& \Delta \mathrm{E}_{\mathrm{Bt}}=2.073+0.0709 \mathrm{Z}_{\mathrm{t}-1}-0.09 \Delta \mathrm{E}_{\mathrm{Bt}-1}+0.0024 \Delta \mathrm{E}_{\mathrm{Bt}-2}+0.067 \Delta \mathrm{E}_{\mathrm{NBt}-1}-0.07 \Delta \mathrm{E}_{\mathrm{NBt}-2}
\end{aligned}
$$

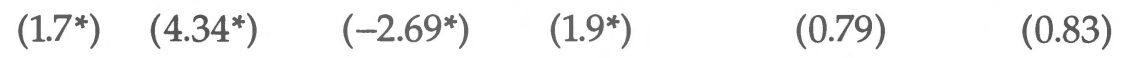

$$
\begin{aligned}
& \hat{\rho}=-0.00623 \quad R^{2}=0.323
\end{aligned}
$$

LM (autocorrelation) $\chi^{2}(4)=0.1604$

\section{Lincoln County:}

$$
\begin{aligned}
\Delta \mathrm{E}_{\mathrm{NBt}}= & 7.9377+0.037 \mathrm{Z}_{\mathrm{t}-1}-0.034 \Delta \mathrm{E}_{\mathrm{Bt}-1}-0.203 \Delta \mathrm{E}_{\mathrm{Bt}-2}-0.18 \Delta \mathrm{E}_{\mathrm{NBt}-1}-0.25 \Delta \mathrm{E}_{\mathrm{NBt}-2} \\
& (1.64) \quad\left(2.97^{*}\right) \quad(-0.35) \quad\left(-2.87^{*}\right) \quad\left(1.93^{*}\right) \\
& \hat{\rho}=-0.00838 \quad \mathrm{R}^{2}=0.126
\end{aligned}
$$

$\mathrm{LM}$ (autocorrelation) $\chi^{2}(4)=3.76$

$$
\begin{aligned}
\Delta \mathrm{E}_{\mathrm{Bt}}= & -2.34-0.028 \mathrm{Z}_{\mathrm{t}-1}+0.07 \Delta \mathrm{E}_{\mathrm{Bt}-1}+0.011 \Delta \mathrm{E}_{\mathrm{Bt}-2}+0.025 \Delta \mathrm{E}_{\mathrm{NBt}-1}-0.202 \Delta \mathrm{E}_{\mathrm{NBt}-2} \\
& (-0.84)\left(-2.53^{*}\right) \quad\left(1.78^{* *}\right) \quad\left(2.04^{*}\right) \\
& \hat{\rho}=-0.0030 \quad \mathrm{R}^{2}=0.1525
\end{aligned}
$$

LM (autocorrelation) $\chi^{2}(4)=3.72$

Nye County:

$\Delta \mathrm{E}_{\mathrm{NBt}}=-0.200-0.1137 \mathrm{Z}_{\mathrm{t}-1}-0.0066 \Delta \mathrm{E}_{\mathrm{Bt}-1}-0.070 \Delta \mathrm{E}_{\mathrm{Bt}-2}-0.0606 \Delta \mathrm{E}_{\mathrm{NBt}-1}-$

$$
\begin{aligned}
& \begin{array}{lllll}
(0.2002) & \left(-4.602^{*}\right) & (-0.3804) & \left(3.905^{*}\right) & \left(-9.406^{*}\right)
\end{array} \\
& 0.299 \Delta \mathrm{E}_{\mathrm{NBt}-2} \\
& \left(-4.64^{*}\right) \\
& \hat{\rho}=-0.06864 \quad R^{2}=0.4036
\end{aligned}
$$

LM (autocorrelation) $\chi^{2}(4)=1.95$

$$
\begin{aligned}
\Delta \mathrm{E}_{\mathrm{Bt}}= & -2.184+0.055 \mathrm{Z}_{\mathrm{t}-1}+0.4851 \Delta \mathrm{E}_{\mathrm{Bt}-1}-0.515 \Delta \mathrm{E}_{\mathrm{Bt}-2}+0.002 \Delta \mathrm{E}_{\mathrm{NBt}-1}- \\
& (-0.84) \quad(0.3171) \quad\left(7.448^{*}\right) \\
& 0.0571 \Delta \mathrm{E}_{\mathrm{NBt}-2} \\
& (-0.6258) \\
\hat{\rho}= & -0.10171 \quad \mathrm{R}^{2}=0.3187
\end{aligned}
$$

LM (autocorrelation) $\chi^{2}(4)=1.03$ 
White Pine County:

$$
\begin{aligned}
\Delta \mathrm{E}_{\mathrm{NBt}}= & -0.413-0.063 \mathrm{Z}_{\mathrm{t}-1}-0.044 \Delta \mathrm{E}_{\mathrm{Bt}-1}-0.048 \Delta \mathrm{E}_{\mathrm{Bt}-2}-0.778 \Delta \mathrm{E}_{\mathrm{NBt}-1}+0.343 \Delta \mathrm{E}_{\mathrm{NBt}-2} \\
& (-0.040) \quad\left(-2.28^{*}\right) \quad\left(-1.85^{* *}\right) \quad(-0.8065) \quad\left(-11.84^{*}\right) \\
& \hat{\rho}=-0.07243 \quad \mathrm{R}^{2}=0.414
\end{aligned}
$$

LM (autocorrelation) $\chi^{2}(4)=0.4822$

$$
\begin{aligned}
\Delta \mathrm{E}_{\mathrm{Bt}}= & 0.7356+0.055 \mathrm{Z}_{\mathrm{t}-1}-0698 \Delta \mathrm{E}_{\mathrm{Bt}-1}-0.33 \Delta \mathrm{E}_{\mathrm{Bt}-2}-0.057 \Delta \mathrm{E}_{\mathrm{NBt}-1}-0.066 \Delta \mathrm{E}_{\mathrm{NBt}-2} \\
& (1.23) \quad\left(2.13^{*}\right) \quad\left(-10.97^{*}\right) \quad\left(-4.99^{*}\right) \quad(-1.067) \\
& \hat{\rho}=-0.07219 \quad \mathrm{R}^{2}=0.3458
\end{aligned}
$$

LM (autocorrelation) $\chi^{2}(4)=7.72$

Numbers in parentheses are ratios of a coefficient to its asymptotic standard error. A (*) signifies significance at $\alpha=0.5$ while $\left(^{* *}\right)$ indicates significance at $\alpha=0.10$. R2 is the standard squared multiple correlation of statistic associated with the regression. LM is the Lagrange multiplier test for residual autocorrelation. The $5 \%$ critical value for chi-squared distribution with four degrees of freedom is 9.488 .

In particular, estimated coefficients of Table 6 can be interpreted as follows. For Nye County, the coefficient for $Z_{t-1}$ in the first equation in the weight for adjustment to a disequilibrium between basic employment and nonbasic employment. The same argument holds for nonbasic employment in the second equation. Notice that the coefficients on the error terms are reasonably substantial and statistically significant at conventional levels. The signs of the coefficients have interesting implications. From Banerjee et al. (1993), the coefficient of -0.1137 for $Z_{t-1}$, in the $\Delta \mathrm{E}_{\mathrm{NBt}}$ equation suggests that as basic employment activity grows above nonbasic employment for the previous month, the rate of growth is higher in contemporary nonbasic employment. That is, as basic employment grows relative to the trend in nonbasic employment series, growth in nonbasic employment will occur. The error when partially corrected is this discrepancy. On the other hand, estimated coefficients on the short-term variables measure the rate of growth of the dependent variable or $\mathrm{E}_{\mathrm{NBt}}$ per unit of time (1 month, 2 months) given a unit change in the exogenous variable. In other words, these are the multiplier accelerators. Therefore, in the short run, a one-unit change in basic employment in the previous month in Nye County will lead to a 0.0066 rate of decrease in nonbasic activity. Similarly, a unit change in nonbasic employment in Nye County one month ago will correspond to a 0.0606 rate of decrease of nonbasic employment.

Notice that none of the regressors in either equation are dated for the current time period. Since there is no evidence of residual autocorrelation from the LM test for fourth-order autocorrelation, the overall performance of the ECM base model is quite impressive.

\section{Granger Test for Causality Between Basic and Nonbasic Sectors}

Table 7 shows the Granger test for causality between basic and nonbasic employment for the five rural counties. For the export-base hypothesis that basic employment Granger causes nonbasic employment, all the counties except for 
White Pine County pass the test at the $5 \%$ level. The joint F-test supports this hypothesis that basic employment Granger causes nonbasic employment in Elko, Eureka, Lincoln, and Nye Counties.

\section{TABLE 7}

Granger Test for Causality for Basic and Nonbasic Employment Sectors for Elko, Eureka, Lincoln, Nye, and White Pine Counties

\begin{tabular}{lcc}
\hline County & $\mathrm{F}_{\mathrm{ENB}}(3,269)$ & $\mathrm{F}_{\mathrm{EB}}(3,269)$ \\
\hline Elko & 21.39 & 0.43 \\
Eureka & 10.97 & 1.23 \\
Lincoln & 7.08 & 2.23 \\
Nye & 7.04 & 0.75 \\
White Pine & 1.96 & 1.17 \\
\hline
\end{tabular}

$\mathrm{F}_{\mathrm{ENB}}$ is a test of the null hypothesis that the parent parameters $\lambda_{1}, \lambda_{1}, \ldots \forall_{\mathrm{j}}=1,2$ in equation 31 are zero; and $\mathrm{F}_{\mathrm{EB}}$ is a test of the null hypothesis that the parent parameters $\gamma_{2}, \alpha_{1}, \ldots \forall_{\mathrm{j}}=1,2$ in equation 32 are zero.

The $5 \%$ critical value for $F[3,269]$ is 2.60 .

\section{Forecasting Experiments}

In-sample estimation of the ECM models was performed from January 1970 to December 1989. In order to test the predictive power of the model, an ex ante forecast was employed using the time period of January 1990 to December 1992.

For forecasting, the model is re-estimated by adding one additional month to the sample. The multistep forecast was for 36 months. According to Engle and Yoo (1987), a multistep forecast of this kind has an intuitive appeal because the forecast error variance for this linear combination is minimized while that for all other linear combinations goes to infinity as the horizon goes to infinity. This process of estimating, updating, and forecasting was performed for 36 months in order to simulate the performance of this model in actual monthly use. The forecasted values of differenced nonbasic activity were transformed into levels to compare the actual values to the predicted values.

Summary statistics for the ex ante forecast are shown in Table 8. A diagnostic-statistic analysis was performed using the Theil $U$ statistic to measure the accuracy of the forecast experiment. Theil's $U$ has values between zero and one. The lower the value of the statistic, the more accurate the forecast. Pindyck and Rubinfeld (1981) suggest that values of 0.3 or less are acceptable as accurate forecasts. Other diagnostic techniques used to measure the accuracy of the forecasting model include the root mean squared percentage error (RMSPE) and mean simulation percentage error (MPE). The RMSPE and MPE measure how closely individual variables track their corresponding data series. This measures the mean and square root deviation of the simulated variable $\mathrm{E}_{\mathrm{NBt}}$ from its actual path.

From Table 8, the calculated Theil U coefficient for each of the five counties is less than 0.3. This indicates that the forecasts of the confirmatory ECM model produce acceptable forecasts. Also, values of the RMSPE and MPE for all five counties employing the confirmatory ECM model indicate acceptable basic and nonbasic sector employment forecasts.

Examination of the forecasts of the confirmatory ECM model as shown in Table 8 gives information about our model forecasting accuracy. However, it would 
be of more interest to compare ex ante forecasts of the confirmatory ECM models to ECM model forecasts by each of the five basic sector employment estimationprocedures. Also, each of these forecasting analyses will be completed for the five rural Nevada counties. ${ }^{1}$

\section{TABLE 8}

Summary Statistics of Ex Ante Forecasts

\begin{tabular}{llcccc}
\hline & Elko & Eureka & Lincoln & Nye & White Pine \\
\hline RMSPE $^{*}$ & $0.73 \%$ & $0.40 \%$ & $2.79 \%$ & $.096 \%$ & $0.126 \%$ \\
MPE ** & $3.8 \%$ & $1.47 \%$ & $20 \%$ & $0.5 \%$ & $-0.0062 \%$ \\
Theil U & 0.022 & 0.011 & 0.082 & 0.0028 & 0.007 \\
\hline
\end{tabular}

${ }^{*}$ RMSPE is root mean squared percentage error, which is the square root of the average of the squared differences between forecast and observed values expressed as a percentage of observed value.

${ }^{*}$ MPE is mean percentage error, which is the average of differences between forecasted and observed values expressed as a percentage of observed values.

In earlier research by Ebai (1995), ECM models for the five Nevada rural counties were estimated for each of the five export-base or basic sector employment procedures. For each of the five rural Nevada counties, the excess location quotient or Theil location quotient procedure derived the best estimation of nonbasic sector employment. Table 9 shows the summary statistics of the ex ante forecasts from the excess location quotient procedure for the five rural Nevada counties. Comparing summary statistics of the Theil U coefficient, RMSPE, and MPE, the confirmatory ECM model had better forecasts.

TABLE 9

Summary Statistics of Ex Ante Forecasts from Excess Location Quotient Procedures (BASE 4)

\begin{tabular}{llcccc}
\hline & Elko & Eureka & Lincoln & Nye & White Pine \\
\hline RMSPE $^{*}$ & $1.58 \%$ & $4.96 \%$ & $4.73 \%$ & $1.02 \%$ & $4.00 \%$ \\
MPE & $6.67 \%$ & $-19.64 \%$ & $21.56 \%$ & $0.73 \%$ & $-6.14 \%$ \\
Theil U & 0.044 & 0.169 & 0.129 & 0.031 & 0.126 \\
\hline
\end{tabular}

${ }^{*}$ RMSPE is root mean squared percentage error, which is the square root of the average of the squared differences between forecast and observed values expressed as a percentage of observed value.

${ }^{*}$ MPE is mean percentage error, which is the average of differences between forecasted and observed values expressed as a percentage of observed values.

\section{CONCLUSIONS}

The objective of this study was to investigate the ability of an export-base model to incorporate both the long-run equilibrium relationships as well as the short-run dynamic interactions between basic and nonbasic employment through ECM modeling. The study brings together time series methodologies with CFA to examine the time dimension in export-base analysis. This study departs from previous work by LeSage (1990), Brown, Coulson, and Engle (1992), Heonsoo (1994), and Nishiyama (1997) in two ways. First, this study was in rural or small area economies, which may be more appropriate for export-base analysis. Second, this study departed from Brown, Coulson, and Engle (1992) and Heonsoo (1994), which examined relationships between total employment and basic employment, in that this paper introduced CFA to bifurcate employment between basic and

\footnotetext{
${ }^{1}$ Comparison of forecasting accuracy investigated results across areas of rural Nevada. As Taylor (1982) warns, forecasting accuracy may vary across regions. However, CFA is invariant to regional and economic characteristics and therefore can be applied to metropolitan as well as nonmetropolitan areas.
} 
nonbasic sectors. Through this bifurcation procedure a truer relationship through time between the two sectors can be derived.

Results of the indicator model for all five rural Nevada counties showed promise in the bifurcation of county employment data between basic and nonbasic sectors. Through cointegration, the export-base models for these five counties indicated long-run stability between the two variables. The ECM model for the five counties provided a vehicle to test Granger causality between basic and nonbasic employment. The Granger causality test indicated unidirectional flow of basic and nonbasic employment for four of the five counties. The results suggest improved export-base forecasting by incorporating indicator model and ECM procedures. In addition, confirmatory model forecasting results proved better than the best of the individual five basic sector employment procedures. The superior forecasting results of confirmatory analysis are not surprising since confirmatory procedures incorporate systematic correction factor as well as errors of each indicator in estimation of basic employment. Results also show that publicly available data and rather low-cost bifurcation estimation procedures may be appropriate for employment forecasts for many rural economies through ECM procedures.

\section{REFERENCES}

Andrews, R.B. "The Problem of Base Measurement." Reprint in R.W. Pfouts (ed.) The Techniques of Urban Analysis, pp. 65-80. West Trenton, NJ: ChandlerDavis, 1970.

Banerjee, A., J.J. Dolado, J.W. Galbraith, and D.F. Hendry. Co-Integration, Error Correction, and the Econometric Analysis of Non-Stationary Data. Advanced Texts in Economics. Oxford: Oxford University Press, 1993.

Blumenfeld, H. "The Economic Base of the Metropolis." Journal of the American Institute of Planners 21 (1995), 114-132.

Bollen, K.A. Structural Equations with Latent Variables. New York: John Wiley, 1989. Braschler, C. "A Comparison of Least Square Estimates of Regional Employment Multipliers with Other Methods." Journal of Regional Science 12 (1972), 457-468. Brown, S.J., N.E. Coulson, and R.F. Engle. "On the Determination of Regional Base and Regional Base Multipliers." Regional Science and Urban Economics 22 (1992), 619-635.

Charemza, W., and D. Deadman. New Directions in Economic Practice: General to Specific Modelling, Cointegration and Vector Autoregression. Aldershot, UK: Edward Elgar, 1992.

Cook, T. "An Application of the Transfer Function to an Economic-Base Model." Annals of Regional Science 13 (1979), 81-92.

Dickey, D. A., and W. A. Fuller. "Distribution of the Estimators for Autoregressive Time Series with a Unit Root." Journal of the American Statistical Association 74 (1979), 427-431.

Ebai, G.E. "Determining Export Base and Export Base Multipliers in Rural Nevada Counties." Masters thesis, University of Nevada, Reno, 1995. 
Engle, R.F., and C.W.J. Granger. "Co-integration and Error Correction: Representation, Estimation and Testing." Econometrica 55 (1987), 251-276. . Long-Run Economic Relationships: Readings in Co-Integration. New York: Oxford University Press, 1991.

Engle, R.F., and J.V. Issler. "Estimating Common Sectoral Cycles." Journal of Monetary Economics 35 (1995), 83-113.

Engle, R.F., and B.S. Yoo. "Forecasting and Testing in Co-integrated Systems." Journal of Econometrics 35 (1987), 143-159.

Giarrantani, F., and P. McNelis. "Time Series Evidence Bearing on Crude Theories of Regional Growth." Land Economics 56 (1980), 238-248.

Gibson, L.J., and M.A. Worden. "Estimating the Economic Base Multiplier: A Test of Alternative Procedures." Economic Geography 57 (1981), 146-159.

Granger, C.W.J. "Investigating Causal Relations by Econometric Models and Cross-Spectral Methods." Econometrica 37 (1969), 424-38.

"Cointegrated Variables and Error Correcting Models." UCSD Discussion Paper 83-13, 1983.

. "Developments in the Study of Cointegrated Variables." Oxford Bulletin of Economics and Statistics 48 (1986), 213-228.

Granger, C.W.J., and P. Newbold. "Spurious Regressions in Econometrics." Journal of Econometrics 2 (1974), 111-20.

Hendry, D., and G. Anderson. "Testing Dynamic Specification in Small Simultaneous Models: An Application to a Model of Building Society Behavior in the United Kingdom." Ch. $8 \mathrm{c}$ in M.D. Intrilligator (ed.) Frontiers of Quantitative Economics. Vol. 3 (a), pp. 3, 361-383. Contributions to Economic Analysis. Amsterdam: North Holland, 1977.

Henry, M., and J. Nyankori. "The Existence of Short-Run Economic Base Multipliers: Some New Empirical Evidence." Land Economics 57 (1981), 448-458.

Heonsoo, P. "Long-Run Base Multipliers and the Determination of the Base of the Economic Base Theory: A Cointegration Analysis." Selected paper at the 1994 WRSA meeting, Tucson, Arizona, February 1994.

Isserman, A.M. "Alternative Economic Base Bifurcation Techniques: Theory, Implementation, and Results." In S. Pleeter (ed.) Economic Impact Analysis: Methodology and Applications, pp. 32-53. Boston, MA: Martinus Nijhoff, 1980.

Krikelas, A.C. "Industry Structure and Regional Growth: A Vector Autoregression Forecasting Model of the Wisconsin Regional Economy." Ph.D. diss., University of Wisconsin-Madison, 1991.

. "Why Regions Grow: A Review of Research on the Economic Base Model." Economic Review: Atlanta Federal Reserve Bank (1992), 16-28.

LeSage, J.P. "Forecasting Metropolitan Employment Using an Export-Base ErrorCorrection Model." Journal of Regional Science 30 (1990), 307-323.

LeSage, J.P., and J.D. Reed. “The Dynamic Relationship Between Export, Local and Total Area Employment." Regional Science and Urban Economics 19 (1989), 615-636. 
Mandelbaum, T.B., and D.L. Chicoine. "The Effect of Time Frame in the Estimation of Employment Multipliers." American Agricultural Economics Association National Meetings, Ames, Iowa, 1985.

McNulty, J. "A Test of the Time Dimension in Economic Base Analysis." Land Economics 63 (1977), 358-368.

Moore, C.L. "A New Look at the Minimum Requirements Approach to Regional Economic Analysis." Economics Geography 51 (1975), 350-356.

Mulligan, G.F., and H.H. Kim. "Sectoral-Level Employment Multipliers in Small Urban Settlements: A Comparison of Five Models." Urban Geography 12 (1991), 240-259.

Nelson, C., and C. Plosser. "Trends and Random Walks in Macroeconomic Time Series: Some Evidence and Implications." Journal of Monetary Economics 10 (1982), 139-162.

Nishiyama, Y. "Exports' Contribution to Economic Growth: Empirical Evidence for California, Massachusetts, and Texas Using Employment Data." Journal of Regional Science 37 (1997), 99-126.

North, D.C. "Location Theory and Regional Economic Growth." Journal of Political Economy 63 (1955), 243-258.

Park, S.H. "Least Squares Estimates of the Regional Employment Multiplier: An Appraisal." Journal of Regional Science 10 (1970), 365-374.

Phillips, A.W. "Stabilization Policy and the Time Forms of Lagged Responses." Economics Journal 47 (1957), 119-29.

Pindyck, R.S., and D.L. Rubinfeld. Econometric Models and Economic Forecasts. New York: McGraw-Hill Book Co., 1981.

Polzin, P.E., K. Connaughton, C.H. Schallau, and J.T. Sylvester. "New Tests of Time Dimension in Economic Base Analysis." Paper presented at the 27th Annual Meeting of the Western Regional Science Association, Napa Valley, California, 1988.

Pratt, R. "An Appraisal of the Minimum Requirements Technique." Economic Geography 44 (1968), 177-224.

Richardson, H.W. "Economic Base and Input-Output Models." Journal of Regional Science 25 (1985), 607-662.

Sargan, J.D. "Wages and Prices in the U.K.: A Study in Econometric Methodology." In P.E. Hart, G. Mills, and J.K. Whitaker (eds.) Econometric Analysis for National Economic Planning. London: Butterworths, 1964.

Schmidt, J.R. "Stochastic and Deterministic Trends in State Economies." Growth and Change 26 (1995), 59-76.

Shahidsaless, S., W. Gillis, and R.E. Shaffer. "Community Characteristics and Employment Multipliers in Non-metropolitan Counties, 1950-1970." Land Economics 59 (1983), 84-93.

Shonkwiler, J.S., and C.B. Moss. "A Multidimensional Index of Financial Stress in the Farm Sector." Social Indicators Research 29 (1993), 307-316. 
Spreen, T., and D. Mulkey. "The Lagged Effect of Basic Sector Employment Change in a Regional Economy." Paper presented at the Southern Regional Science Association Meetings, Savannah, Georgia, 1980.

Taylor, C.A. "Regional Econometric Model Comparisons: What Do They Mean?" Annals of Regional Science 16 (1982), 1-15.

Tiebout, C.M. "Exports and Regional Economic Growth." Journal of Political Economy 64 (1956), 160-69.

. "The Community Economic Base Study." Committee for Economic Development Supplementary Paper 16. New York, 1962.

Ullman, E., and M. Dacey. "The Minimum Requirements Approach to the Urban Economic Base." Papers of the Regional Science Association 6 (1960), 175-194.

Woods, M.D., G.A. Doeksen. and L.L. Jones. "A Presentation and Comparison of Three Computer Models Developed to Model the Social and Economic Impacts of Rural Community Growth." The Review of.Regional Studies 13 (1983), 22-31. 